\title{
Tecnologias Móveis para Alfabetização: Apontamentos sobre o Aplicativo Palma
}

\author{
Mobile Technologies for Literacy: Notes about the Palma Application
}

Ana Graciela M. F. da Fonseca Voltolini ${ }^{a}$; José Serafim Bertoloto*a; Ed Wilson Rodrigues Silva Júnior ${ }^{\mathrm{a}}$

\author{
aUniversidade de Cuiabá, Programa de Pós-Graduação Stricto Sensu em Ensino. MT, Brasil. \\ *E-mail: serafim.bertoloto@gmail.com. \\ Recebido em: 04/06/19; Aceito em: 23/09/19
}

\begin{abstract}
Resumo
A partir do desenvolvimento das Tecnologias Digitais de Informação e Comunicação - TDIC, esses dispositivos oferecem novos recursos e possibilidades também para o ensino, através de celulares, de smartphones, de tablets e de aplicativos, por exemplo. A UNESCO é grande incentivadora do uso de tecnologias e de recursos móveis para apoiar, facilitar e promover o acesso aos materiais e aos conteúdos educacionais. Nesse cenário, o presente artigo apresenta apontamentos sobre o Aplicativo Palma, um recurso para dispositivos móveis que auxilia na alfabetização na língua materna. Trata-se de um artigo bibliográfico e documental que analisa essa ferramenta de apoio ao processo de ensino e aprendizagem inserida no conceito de Aprendizagem Móvel. De acordo com o estudo, a opção por um dispositivo móvel, acessível, e a utilização de uma interface simples, amigável, indica um caminho para inserção significativa das tecnologias móveis no contexto educacional, sobretudo, para pessoas com pouca ou nenhuma alfabetização.
\end{abstract}

Palavras-chave: Dispositivos Móveis. Aprendizagem Móvel. Ensino.

\begin{abstract}
From the development of Digital Information and Communication Technologies - TDIC, these devices offer new features and possibilities for teaching, through cell phones, smartphones, tablets and applications, for example. UNESCO strongly encourages the use of mobile technologies and resources to support, facilitate and promote access to educational materials and content. In this scenario, this article presents notes about the Palma Application, a resource for mobile devices that assists in literacy in the mother tongue. It is a bibliographical and documentary article that analyzed this support tool to the process of teaching and learning inserted in the concept of Mobile Learning. According to the study, the choice of an accessible mobile device and the use of a simple, user-friendly interface indicate a path for meaningful insertion of mobile technologies into the educational context, especially for people with little or no literacy.
\end{abstract}

Keywords: Mobile devices. Mobile Learning. Teaching.

\section{Introdução}

Este artigo propõe, por meio de um estudo bibliográfico e documental, e como exemplo o Aplicativo Palma, uma reflexão sobre como a evolução tecnológica, notadamente, a explosão dos dispositivos móveis, fornecendo novos produtos e serviços convergentes, que permitiram o surgimento de novas possibilidades de ensino e aprendizagem, denominadas de Mobile Learning - Aprendizagem Móvel.

A recomendação e a utilização de dispositivos móveis crescem em função de rápida expansão e de barateamento dessas tecnologias. Multimídia, portáteis e familiares, smartphones e tablets representam alternativas a serem exploradas para o ensino. Palamedi (2013) destaca a presença dessas ferramentas no cotidiano, que configuram e reconfiguram nossos hábitos diários e com as quais se estabelece e se executam as mais diversas tarefas e atividades. Contudo, essas ferramentas precisam ser de simples manuseio para a compreensão de suas funcionalidades e recursos, assim são mais facilmente aceitas pelo usuário.
A partir dos dispositivos móveis surge o Mobile Learning ou Aprendizagem Móvel, uma modalidade de ensino que permite ao aluno acessar materiais, assistir aulas síncronas e assíncronas, interagir em qualquer lugar e a qualquer tempo (TAROUCO et al., 2004).

Nesse universo, o Programa Palma propõe contribuir na alfabetização na língua materna, através de um aplicativo para dispositivos móveis, que combina sons, letras e imagens para apoio ao processo de ensino e aprendizagem para pessoas em fase inicial de alfabetização ou com dificuldades.

A partir dos pressupostos, que norteiam o aplicativo e referencial teórico a respeito da temática, foi possível analisar os aspectos relacionados à concepção do Palma e na escolha do suporte do conteúdo via dispositivo móvel, ambos pautados no conceito da Aprendizagem Móvel.

\section{Desenvolvimento}

\subsection{Metodologia}

Para analisar a Aprendizagem Móvel, que tem levado smartphones e tablets a serem recomendados e utilizados 
também para o processo de ensino e aprendizagem, foi realizada uma pesquisa de natureza qualitativa, do tipo exploratória, com base no Aplicativo Palma.

A pesquisa buscou, a partir do referido aplicativo, verificar características e aspectos relacionados à recomendação e ao uso de dispositivos móveis para o ensino. De acordo com Gil (2008), a pesquisa exploratória é desenvolvida com o objetivo de proporcionar visão geral, de aproximação em relação a um fato. Usualmente, pesquisas desse tipo podem envolver levantamento bibliográfico e documental, entrevistas não padronizadas e estudos de caso.

O elemento que identifica o delineamento da pesquisa é o procedimento adotado para a coleta de dados. Dessa forma, caracteriza-se a pesquisa como bibliográfica e documental. A pesquisa bibliográfica é desenvolvida com base em material já elaborado e a documental se vale de materiais, que não recebem ainda um tratamento analítico. Nesse caso, as informações obtidas e utilizadas no estudo se aproveitaram de fontes de "papel”, como livros, artigos, além de relatórios (GIL, 2002).

\subsection{Discussão}

Sharples, Taylor e Vavoula (2005) destacam três eras de aprendizagem mediada por recursos da comunicação. $\mathrm{Na}$ primeira, a era da alfabetização em massa, o livro foi o meio de instrução e o objetivo principal do sistema de educação era a transmissão de informação. Na segunda, a era do computador, a educação é reconceituada em torno da construção do conhecimento, através da modelagem de informações, de processamento e de interação. A terceira é a era móvel, na qual a educação é concebida como uma conversa em contexto, habilitada pela interação contínua através da tecnologia pessoal e móvel.

Os autores Carvalho, Galvanin e Santos (2018) argumentam que na busca por otimizar espaço e tempo, as tecnologias móveis ganham força e fazem emergir o conceito de Aprendizagem Móvel (Mobile Learning ou M-Learning). O estudo Activando el Aprendizaje Móvil: Temas Globales (UNESCO, 2012) coloca que a década atual é marcada pelos avanços das tecnologias móveis, em que características como onipresença e portabilidade as colocam frente às demais.

Considerando as afirmações, o Palma - Programa de Alfabetização na Língua Materna é uma ferramenta voltada para o processo de alfabetização suportada por dispositivos móveis (smartphones e/ou tablets). Trata-se de um aplicativo, que combina sons, letras e imagens, possui um sistema de acompanhamento das atividades direcionado aos professores, pais/responsáveis e outros profissionais, que trabalham com aprendizagem, como: fonoaudiólogos e professores particulares.

O aplicativo foi criado para contemplar pessoas em fase inicial de alfabetização ou com dificuldades de aprendizagem. Primeiramente, o público-alvo do programa foram alunos na modalidade Educação de Jovens e Adultos - EJA, porém, atualmente, o aplicativo está disponível para outros públicos, a partir de três versões: Palma ESCOLA, Palma ABC e Palma PRO.

Idealizado pelo matemático José Luís Poli, cofundador da Anhanguera Educacional e desenvolvido pela empresa IES2, após a fase de testes, o programa diversificou o dispositivo utilizado e ampliou o público inicial (PRADO, 2014). Desde 2015, esse dispositivo está disponível e comercializado através de download em lojas de aplicativos.

Antes da comercialização, a empresa desenvolvedora realizou pilotos, que ocorreram em sete municípios do Estado de São Paulo: Itatiba, Pirassununga, Campinas, Araras, Franca, Santos e Ourinhos, além de João Pessoa, na Paraíba, onde o Palma foi utilizado como apoio para a alfabetização de profissionais da construção civil.

Jovens e adultos de algumas escolas públicas de cidades do interior de São Paulo, em estágio inicial de alfabetização, receberam gratuitamente um celular para acessarem, diariamente, o aplicativo instalado nesse dispositivo. Lições sonorizadas, desenvolvidas com o método fônico, complementam a alfabetização em cinco níveis: alfabeto, sílabas simples e complexas, vocabulário e interpretação de texto.

Figura 1 - Jovens e adultos usando o Palma em uma escola municipal de Campinas

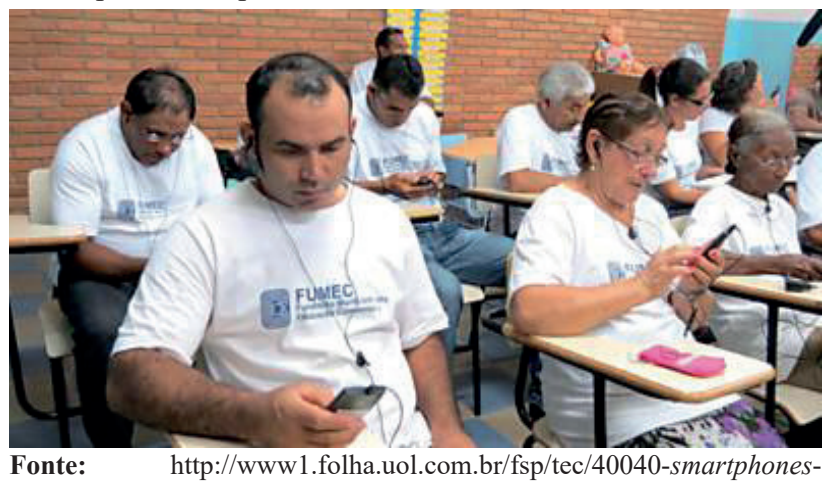
auxiliam-na-alfabetizacao.shtml.

No caso de João Pessoa, a utilização do Palma foi uma parceria entre a IES2, a Universidade Federal da Paraíba, o Programa Escola Zé Peão e a Cátedra da UNESCO de Educação de Jovens e Adultos, através do projeto AMCO Aprendizagem Móvel no Canteiro de Obras. A parceria teve como objetivo a investigação sobre o uso de dispositivos móveis, enquanto suportes complementares ao processo de alfabetização e de inclusão digital. Para fins de pesquisa, em 2013, o Palma foi implementado, experimentalmente, em duas salas de aula do Programa Escola Zé Peão.

Rachid e Ishitani (2012) destacam que nem todo mundo pode frequentar um curso regular, além da necessidade do aprendizado contínuo. Pensado no sentido de apoio e de complemento do processo de ensino-aprendizagem, iniciativas como o Aplicativo Palma podem facilitar, 
representam ampliação e diversificação de recursos educacionais. A Aprendizagem Móvel já provou ser capaz de levar a aprendizagem para pessoas, comunidades e países, que antes estavam demasiado afastados, reforçar e enriquecer atividades, através de experiências mais personalizadas, autênticas, situadas e sensíveis ao contexto.

De acordo com o coordenador da iniciativa, em João Pessoa, o professor Timothy Ireland (2015, p.7), da Universidade Federal da Paraíba:

São poucas as iniciativas brasileiras que atendam a Alfabetização de Jovens e Adultos, tendo por base um 'Universo Mobile'. A utilização do PALMA (Programa de Alfabetização na Língua Materna) teve sua origem no Sudeste do Brasil, especificamente em São Paulo, e fora desenvolvido por um grupo de pesquisadores que, inquietos com as questões de Alfabetização de Adultos, vislumbraram o desenvolvimento de uma ferramenta capaz de atender às demandas de países de Língua Portuguesa que sofrem o descompasso entre desenvolvimento e aprendizagem.

A IES2 destaca que o uso de modernas tecnologias de informação e de comunicação é uma ação de suporte produtivo aos processos de aprendizagem, que visa melhorar e facilitar dentro e fora da sala de aula (PROGRAMA PALMA, 2014). Com a difusão e o leque de funcionalidades embutidos nos dispositivos móveis, propostas, expectativas e argumentos emergem relacionados a sua apropriação para o ensino e aprendizagem. Assim, são desenvolvidas novas expectativas de liberdade, de flexibilidade em relação ao momento e ao local da prática, antes dependente de uma estrutura fixa (SANTAELLA, 2010).

Para os idealizadores, o aplicativo deve ser visto como uma ferramenta que "apoia, complementa e potencializa o trabalho de mediação do professor durante o processo de alfabetização de crianças, jovens e adultos" (PROGRAMA PALMA, 2014). A proposta é proporcionar um recurso que potencialize o processo de alfabetização e que aproxime os conteúdos escolares do cotidiano dos alunos, agregando aspectos lúdicos e interativos.

Um dos aspectos que auxiliam a aprendizagem no aplicativo é o aprendizado por associação de ideias, através do uso de imagens, que auxiliam na compreensão de letras, de sílabas e de palavras.

Figura 2 - Exemplo de Atividade

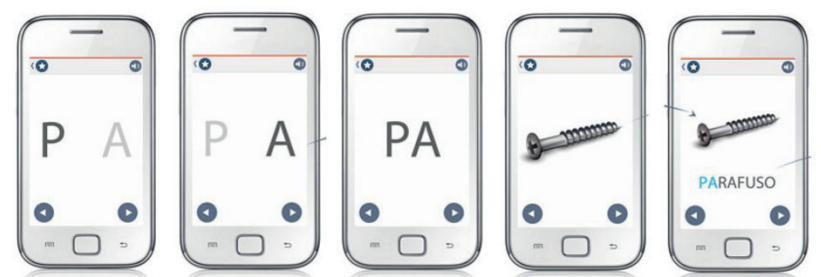

Fonte: Guia de Orientações Didáticas - Palma PRO (2014).

O Palma apoia sua proposta com base nos documentos da UNESCO, grande incentivadora de práticas de Aprendizagem Móvel, que ressaltam o potencial dessas tecnologias aplicadas para esse fim. Essas tecnologias podem ser facilmente encontradas, com um custo acessível, e ainda são de simples manejo. Sendo assim, tornaram-se aparatos comuns no cotidiano, disseminados.

Para o guia Policy Guidelines for Mobile Learning (UNESCO, 2013), os celulares são populares em ambientes nos quais as demais tecnologias são escassas, como em alguns países africanos. Representa uma possibilidade de aprendizagem interrupta, ampliada e teoricamente de baixo custo, com o aproveitamento imediato de uma tecnologia disponível. O telefone celular é, sem dúvida, a tecnologia mais popular e acessível na atualidade "Se o computador ainda é um objeto restrito, o celular está presente em boa parte das escolas, nas mochilas dos alunos de diferentes classes sociais" (MERIJE, 2012, p. 81).

O estudo Activando el Aprendizaje Móvil en América Latina: Iniciativas ilustrativas e implicaciones políticas (UNESCO, 2012) aponta que a maioria das propostas de Aprendizagem Móvel na América Latina é destinada ao apoio e complemento da educação formal, em disciplinas como: Português e Matemática, para alfabetização e letramento de públicos desfavorecidos economicamente ou geograficamente.

De acordo com o Guia Palma PRO (2014), o uso dos dispositivos móveis pode contribuir para uma educação com mais qualidade. O programa acredita não somente na disseminação dos dispositivos móveis, mas também reforça o quanto os recursos agregados a essa tecnologia, como os aplicativos, por exemplo, estão acessíveis.

O Aplicativo investiu em diversos recursos audiovisuais (imagens e sons instrucionais), elementos gráficos intuitivos, que indicam ao usuário o caminho a seguir, como: confirmar, ouvir novamente, arrastar, digitar e recortar palavras, refazer atividades. Dessa forma, o aplicativo é de fácil compreensão e evolui o grau de dificuldade, conforme os resultados das atividades e só é possível prosseguir para a próxima fase se atingir os índices desejáveis de aprendizado.

Figura 3 - Exemplo de ensino da palavra "PRATO" no aplicativo através do uso de figuras (representação gráfica)

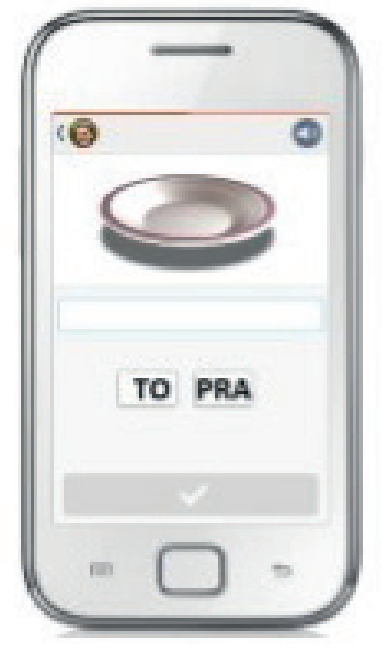

Fonte: Guia de Orientações Didáticas - Palma PRO (2014). 
De acordo com Mülbert e Pereira (2011), as inovações tecnológicas oriundas do desenvolvimento das telecomunicações têm oportunizado acesso a diferentes ambientes e formas de aprendizagem. O que antes dependia de um aparelho ligado a uma estrutura fixa de rede, hoje conta com dispositivos móveis, que também permitem o acesso aos ambientes e aos recursos educacionais similares.

Além disso, os dispositivos digitais móveis reúnem requisitos que os fazem sobressair entre as demais tecnologias, como aponta Fedoce e Squirra (2011, p. 268):

Em relação à produção de novas experiências, destacam-se, entre outras, as mídias móveis, como notebooks, celulares, tocadores de MP3/MP4, iPads, iPods, palmtops e e-book readers, como o Kindle, que permitem maior flexibilidade no processo de comunicação devido às características de mobilidade, interatividade e portabilidade. Atrativos estes, sedimentados por enorme 'amigabilidade' de uso. Desse modo, as tecnologias móveis permitem novas formas de interação com conteúdos, pessoas e ambientes, seja a partir da conexão móvel, de aplicativos de realidade aumentada, sistema GPS, entre outros.

Além da disseminação e da multifuncionalidade, os dispositivos móveis, de acordo com Fedoce e Squirra (2011) se destacam entre as mídias interativas, pois contam, também, com recursos de mobilidade e de portabilidade. Lee et al. (2005) apontam que caso o tamanho represente um empecilho na utilização de um dispositivo, toda a funcionalidade não será suficiente.

A partir desses aparatos, o usuário, nesse contexto aluno/ estudante/aprendiz, passa a ter mecanismos, que propiciam o aprendizado literalmente nas mãos, podendo captar e acessar conteúdos e informações no ambiente em que está e a qualquer hora. Na outra ponta do processo, professor e escola também são impactados, dispondo de mecanismos que contribuem, apoiam e ampliam a tarefa de ensinar, para além dos recursos, dos tempos e de espaços convencionais.

Nos aspectos que envolvem a usabilidade, além dos recursos audiovisuais apontados anteriormente, o projeto parte da percepção do professor José Poli, de que todas as pessoas sabem usar o celular e se as pessoas fazem ligações, usando algarismos de zero a nove, poderiam também associar letras aos números, logo, o programa combina números com letras, imagens, sons e símbolos (PRADO, 2014).

Palamedi (2013) define usabilidade como uma qualidade nos produtos, que permite aos usuários manusear aparelhos ou interagir com sistemas, com facilidade e simplicidade, de forma a atingir seus objetivos e expectativas. De acordo com o autor, quando as dificuldades de operar um dispositivo ou sistema são severas, o uso fica comprometido ou até mesmo impossibilitado. Para ser considerado com boa usabilidade, o dispositivo ou sistema deve ser eficaz na comunicação com o usuário. Lee et al. (2005) colocam que a usabilidade depende do usuário e do dispositivo. O usuário precisa de conhecimento, de capacidade e de habilidade, e o dispositivo/ sistema deve ter ou criar recursos capazes de estabelecer uma relação com o usuário.

Além disso, ao término da aula, o aluno pode continuar as lições em casa, no ônibus, em qualquer lugar, pois o aplicativo está em um dispositivo portátil e pode ser usado no modo offline. Para Rachid e Ishitani (2012), as características da Aprendizagem Móvel são: utilizar dispositivos que podem ser usados em qualquer lugar, de uso pessoal, mais baratos que computadores pessoais e mais fáceis de usar. Andrade (2018, p. 927) aponta que esta modalidade não precisa estar no espaço formal da sala de aula e com a mediação direta do professor "pode ocorrer em outros espaços e em outros tempos, de acordo com a necessidade e o interesse de quem educa e de quem aprende".

O método de alfabetização adotado pelo programa é o fônico. O método fônico consiste no aprendizado por associação entre grafemas (letra, símbolo gráfico utilizado para constituir palavras) e fonemas (unidade sonora utilizada para formar e distinguir palavras), que permite a descoberta do princípio alfabético e, progressivamente, o domínio ortográfico, através de textos. Além disso, o aplicativo faz uso de bases e elementos visuais, que auxiliam no reconhecimento de conjuntos gráficos.

O design foi desenvolvido pensando no público-alvo, alunos em processo de alfabetização. Dessa maneira, o aplicativo evita textos em toda a aplicação, utilizando ícones e navegação intuitiva para que o usuário consiga avançar sem muitas interrupções. O aplicativo faz uso de componentes baseados em uma linguagem icônica, que facilita a orientação de professores/tutores/pais, como também dos usuários, durante o processo de aprendizagem.

Figura 4 - Menu principal

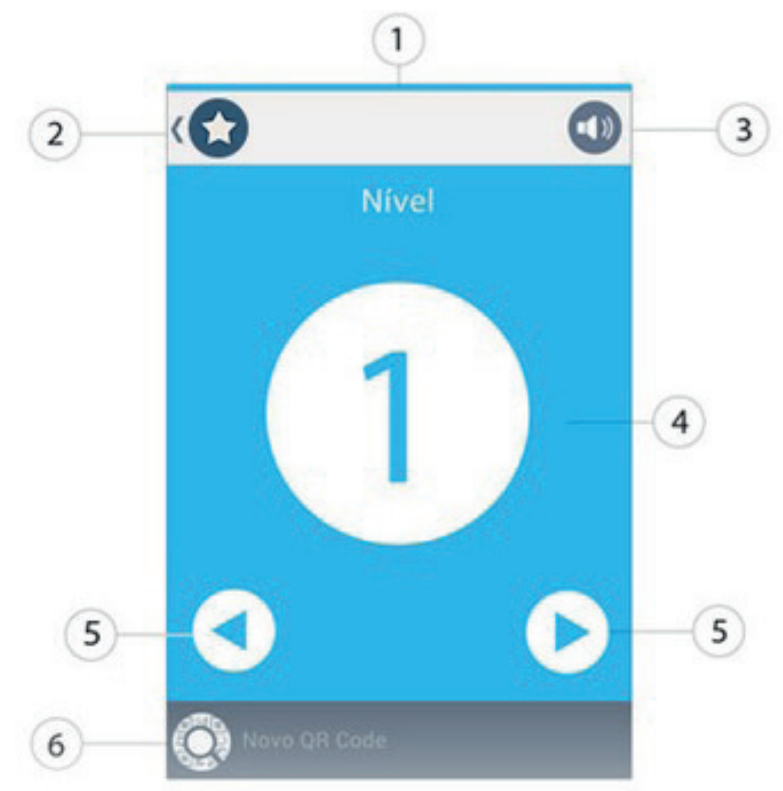

Fonte: http://www.programapalma.com.br/

Há também ícones que servem para orientar as atividades, exemplo na figura abaixo. $\mathrm{O}$ ícone 7 se refere à ilustração $\mathrm{e}$ todas as figuras e letras apresentadas na tela acompanham 
função de áudio ao clicar sobre essas. A tesoura, número 8, para o corte da letra ou sílaba na atividade. O botão 9 é o verificar, que confirma a resposta e avança para a próxima atividade, esses são exemplos utilizados pelo aplicativo, por exemplo.

Figura 5 - Componentes do Design Palma Escola
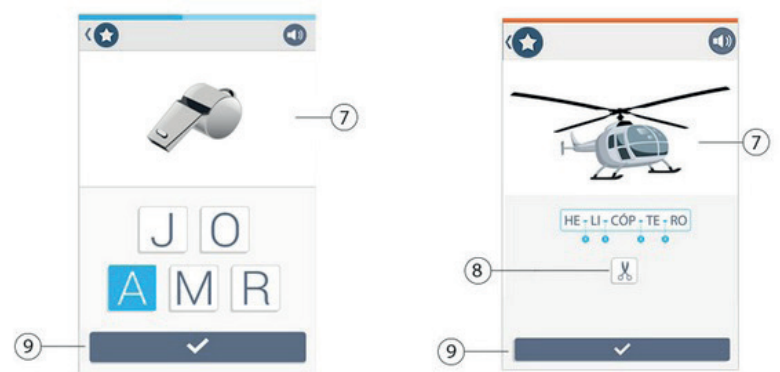

Fonte: http://www.programapalma.com.br/

Para o estudo de Temas Globais da UNESCO (2012), os dispositivos móveis podem enriquecer oportunidades educativas, pois são multimídias e contam com uma gama de funcionalidades, fatores que fazem diferença. Favorecem modelos de aprendizagem personalizados " $1: 1$ " e situados. Assim, como é consenso que o uso desses dispositivos pode ajudar pessoas que carecem de oportunidades educativas, favorecer camadas menos favorecidas, com pouco tempo para se dedicar aos estudos, uma boa estratégia em países subdesenvolvidos ou em desenvolvimento.

A aprendizagem é conduzida por atividades com dificuldades crescentes, que colocam à prova os conhecimentos recém-adquiridos. A opção por essa estratégia permite ao usuário a reconstrução do saber socialmente construído, através de superações sucessivas e crescentes nas diversas fases e níveis durante o uso do aplicativo.

O processo consiste em ir do simples ao complexo, considerando as competências e as habilidades descritas na matriz de referência em Leitura e Escrita do Programa Brasil Alfabetizado do Ministério da Educação. As palavras-chave e o vocabulário utilizado também seguem as recomendações do MEC e foram escolhidas com base nas diferenças regionais, de maneira que não representem um obstáculo na adoção do programa em diversas partes do país (PRADO, 2014).

O conteúdo está organizado em Atividades de Aprendizagem, Fixação, Caligrafia e Integradoras/Jogos, distribuídos em cinco níveis. $O$ aplicativo propõe um aprendizado de forma gradativa, em que os níveis de dificuldade aumentam ao longo do processo de aprendizagem. O aprendizado tem início com a identificação da letra e seu som correspondente, depois se aprende a combinação consoante vogal $(\mathrm{C}-\mathrm{V})$, para, por último, aprender entre duas consoantes e uma vogal (C-C-V).
Figura 6 - Consoante + Consoante + Vogal, Atividade de Aprendizagem

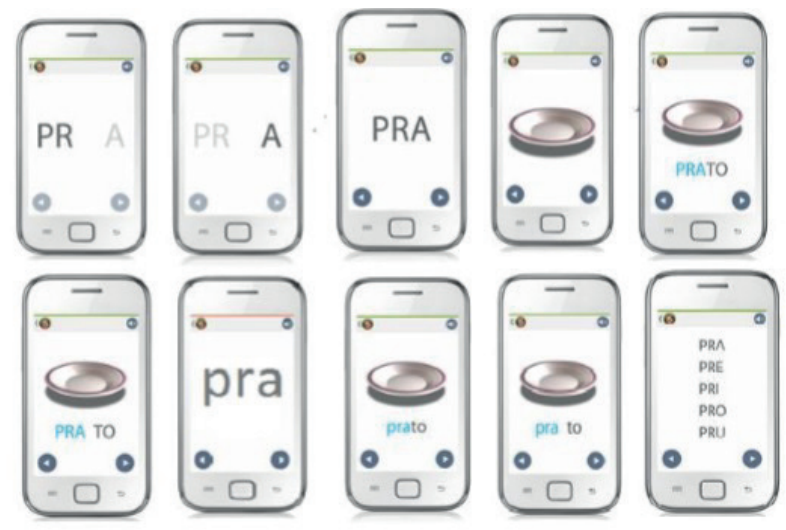

Fonte: Guia de Orientações Didáticas - Palma PRO (2014).

O programa conta um sistema que permite ao professor fazer o acompanhamento do aprendizado do aluno. Em cada fase há testes, que avaliam continuamente o progresso, gerando automaticamente um relatório ao professor, fator que contribuí na tomada de decisão. O relatório permite um acompanhamento individual e específico sobre cada uma das dificuldades detectadas, em relação a cada atividade ou nível.

Figura 7 - Áreas administrativas e avaliação
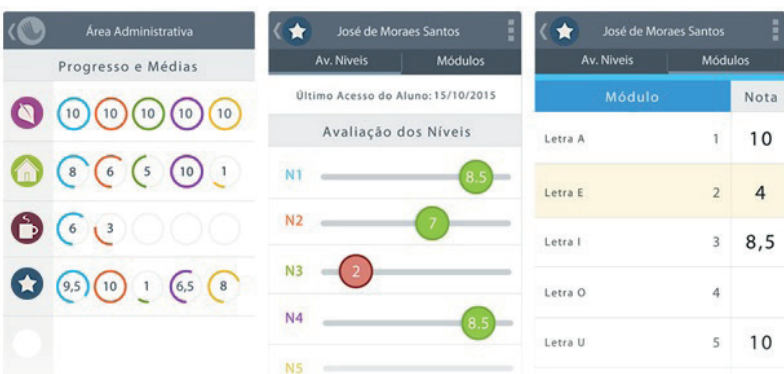

Fonte: Guia de Orientações Didáticas - Palma PRO, 2014.

O aplicativo se apresenta com a capacidade de alavancar a aprendizagem, tanto pelos aspectos da ferramenta, com conteúdo e interface de fácil compreensão, com atividades que vão do simples ao complexo, em que o grau de complexidade aumenta de acordo com o nível; uso de linguagem icônica e aprendizado por associação de ideias, que facilitam e orientam as atividades; gamificação, integrando elementos de jogos, como: níveis, fases e desafios, quanto pelo dispositivo que suporta o aplicativo, smartphones e tablets, considerados populares, amigáveis e disseminados na sociedade. Com isso, de acordo com a IES2, agrega-se a metodologia de ensino, que não é considerada inovadora, inovação e motivação, além de um processo considerado mais contextualizado.

Para Voltolini et al. (2019), apenas a difusão de celulares e de smartphones, por exemplo, não representa algo concreto para a Educação, mas sim o desdobramento desse fato com características intrínsecas a essas tecnologias, como: multimidialidade, multifuncionalidade, mobilidade e portabilidade e acessibilidade - econômica e tecnológica, 
que juntas podem contribuir para o processo de ensino e aprendizagem.

\section{Conclusão}

O ensino e a aprendizagem, anteriormente restritos a salas de aula, sinônimo de espaço para a obtenção de informações e de construção do conhecimento, vêm sendo impactos por novas formas de acesso. A partir da Web e a disseminação dos dispositivos móveis se percebe a busca por conteúdo on-line, sendo a Aprendizagem Móvel, uma possibilidade para tal.

O Palma se apresenta como uma ferramenta de complemento para a educação formal e não deve ser visto como uma solução. Atualmente, é possível encontrar três versões do aplicativo: ESCOLA, PRO e ABC. Na fase piloto, os dispositivos, celulares de um mesmo modelo, foram distribuídos gratuitamente aos alunos, podiam ser levados para casa e já continham o aplicativo instalado.

Oprograma aponta que conseguealavancara aprendizagem, tanto pelos aspectos do recurso, de fácil compreensão, com atividades que vão do simples ao complexo, em que o grau de complexidade aumenta de acordo com o nível; uso de linguagem icônica e aprendizado por associação de ideias, que facilitam e orientam as ações; elementos de gamificação, integrando elementos de jogos, como níveis, fases e desafios; quanto pelo dispositivo que suporta o aplicativo, smartphones e tablets, considerados populares e disseminados.

\section{Referências}

ANDRADE, C. WhatsApp como estratégia de aprendizagem no ensino de História. In: CONGRESSO BRASILEIRO DE INFORMÁTICA NA EDUCAÇÃO, 7. 2018. Fortaleza. Anais... Fortaleza: CBIE, 2018.

CARVALHO, J.N.; GALVANIN, E.A.S.; SANTOS, W.S. Aprendizagem móvel no Brasil: um mapeamento de teses e dissertações. Rev. Bras. Ensino Ciênc. Tecnol., v.11, n.1, p.73-87, 2018. doi: $10.3895 /$ rbect.v11n1.5364

FEDOCE, R.; SQUIRRA, S. A tecnologia móvel e os potenciais da comunicação na educação. LOGOS 35 Mediações Sonoras, v.18, n.2, p.268-278, 2011. doi: //doi.org/10.12957/logos.2011.2264

GIL, A.C. Como elaborar projetos de pesquisa. São Paulo: Atlas, 2002.

GIL, A. C. Métodos e técnicas de pesquisa social. São Paulo: Atlas, 2008.

IRELAND, T. Aprendizagem móvel no canteiro de obra: um estudo de caso da implementação do Programa de Alfabetização em Língua Materna (PALMA) no Programa Escola Zé Peão. João Pessoa: Universidade Federal da Paraíba, 2015.
LEE, V. et al. Aplicações Móveis: arquitetura, projeto e desenvolvimento. São Paulo: Pearson Education do Brasil, 2005.

MERIJE, W. Mobimento: educação e comunicação mobile. São Paulo: Petrópolis, 2012.

MÜLBERT, A.L.; PEREIRA, A.T.C. Um panorama da pesquisa sobre Aprendizagem Móvel (m-learning). In: SIMPÓSIO NACIONAL DA ABCIBER, 5. 2011, Florianópolis. Anais... Florianópolis: UFSC, 2011.

PALAMEDI, F. A usabilidade como instrumento da análise da função comunicativa em interfaces digitais. In: FERREIRA JÚNIOR, J.; SANTOS. M.C.D. Comunicação, tecnologia e inovação: estudos interdisciplinares de um campo em expansão. Porto Alegre: Buqui, 2013. p.63-85.

PRADO, F. Celular alfabetiza jovens e adultos em Itatiba. Porvir, 2014. Disponivel em: http://porvir.org/celular-alfabetiza-jovensadultos-em-itatiba-sp. Acesso em: 4 jan. 2019.

PROGRAMA PALMA. Guia de Orientações Didáticas Palma PRO. IES2. Campinas. 2014.

RACHID, C.L.; ISHITANI, L. m-tutorial: ferramenta de autoria para desenvolvimento de tutoriais voltados para o m-learning. Rev. Bras. Inform. Educ., v.20, n.1, p.17-31, 2012.

SANTAELLA, L. A aprendizagem ubíqua substitui a educação formal? ReCeT - Revista de Computação e Tecnologia, v.11, n.1, p.17-32, 2010.

SHARPLES, M.; TAYLOR, J.; VAVOULA, G. Towards a Theory of Mobile Learning. $4^{\circ}$ World Conference on mLearning. Cape Town: África do Sul, 2005. Disponível em: http://www.mlearn. org/mlearn2005/CD/papers/Sharples-\%20Theory\%20of\%20 Mobile.pdf. Acesso em: 4 jan. 2019.

TAROUCO, L. et al. Objetos de Aprendizagem para M-Learning. In: SUCESU - CONGRESSO NACIONAL DE TECNOLOGIA DA INFORMAÇÃO E COMUNICAÇÃO, 2004. Florianópolis. Anais... Florianópolis, 2004. Disponível em http://www.cinted. ufrgs.br/CESTA/objetosdeaprendizagem_sucesu.pdf. Acesso em: 4 jan. 2019.

UNESCO. Activando el Aprendizaje Móvil en América Latina: Iniciativas ilustrativas e implicaciones políticas. UNESCO, 2012. Disponivel em: http://unesdoc.unesco.org/ images/0021/002160/216080s.pdf. Acesso em: 4 jan. 2019.

UNESCO. Activando el Aprendizaje Móvil: Temas Globales. UNESCO, 2012. Disponivel em: http://unesdoc.unesco.org/ images/0021/002164/216451s.pdf. Acesso em: 4 jan. 2019.

UNESCO. Policy Guidelines for Mobile Learning. Unesco, Paris, p. 41, 2013. Disponivel em: http://unesdoc.unesco.org/ images/0021/002196/219641E.pdf. Acesso em: 4 jan. 2019.

VOLTOLINI, A. et al. Mobile Learning: da sala de aula tradicional à educação na ponta dos dedos. In: CONGRESSO IBERO-AMERICANO SOBRE ECOLOGIA DOS MEIOS, BRASIL. 2019. Disponível em: http://meistudies.org/index.php/ cia/iac/paper/view/255. Acesso em: 9 jan. 2019. 